\title{
Is outcome from ARDS related to the severity of respiratory failure?
}

\author{
M. Ferring, J-L. Vincent
}

Is outcome from ARDS related to the severity of respiratory failure? M. Ferring, J-L. Vincent. CERS Journals Ltd 1997.

ABSTRACT: The characteristics and outcome of acute respiratory distress syndrome (ARDS) may have changed with time. Some studies have reported that mortality is more commonly related to the development of sepsis/multiple organ failure (MOF), and others that it is related to the severity of acute respiratory failure (ARF). The present study evaluates the relative importance of the two phenomena in a large series of patients.

The clinical and biological data of all patients who developed ARDS during a 26 month period (January 1993 until February 1995) in our intensive care unit (ICU) were reviewed retrospectively.

A total of 129 patients developed ARDS during the study period, representing an incidence of $2.4 \%$ of all ICU admissions. The mortality rate was $52 \%$. The primary cause of death was sepsis/MOF (49\%), followed by respiratory failure $(16 \%)$, cardiac failure or arrhythmias (15\%), neurological failure $(\mathbf{1 0 \%})$, and other causes $(8 \%)$. The mortality rate was related to age and degree of organ failure. MOF was not always a cause of late death, since half the deaths occurred within 5 days after admission. In addition, mortality was higher in septic than in nonseptic patients, and lower in trauma and surgical than in medical patients.

We conclude that sepsis/multiple organ failure is still the most common cause of death in acute respiratory distress syndrome. Improvements in outcome of acute respiratory distress syndrome may depend more on treatment of sepsis and multiple organ failure than on oxygenation measures.

Eur Respir J 1997; 10: 1297-1300.

The acute respiratory distress syndrome (ARDS) is still associated with significant rates of morbidity and mortality. Although the fatality rate may have decreased in recent years [1, 2], it still ranges 40-70\% [3-19]. In a landmark article published in 1985, MONTGOMERY et al. [3] reported that, in a series of 47 patients with ARDS, sepsis/multiple organ failure (MOF) was the leading cause of death in these patients, whereas refractory hypoxaemia was responsible for only $16 \%$ of mortalities. Since then, several other investigators have reported similar findings $[3-5,19,20]$, but others have reported respiratory failure as the most frequently lethal event $[4,9]$. In particular, Suchyta et al. [9] reported, in 1992, that refractory hypoxaemia was responsible for $40 \%$ of deaths in a large series of 215 patients with ARDS.

These elements could have profound consequences, since a high rate of refractory hypoxaemia as a cause of death may be a strong incentive to develop more sophisticated methods of temporary respiratory support, with techniques such as extracorporeal membrane oxygenation (ECMO) or extracorporeal $\mathrm{CO}_{2}$ removal $\left(\mathrm{ECCO}_{2} \mathrm{R}\right)$.

The aim of this study was to analyse the mortality of patients recently treated for ARDS in our intensive care unit (ICU), and, in particular, to define the importance of refractory hypoxaemia as a terminal event.
Dept of Intensive Care, Erasme University Hospital, Free University of Brussels, Belgium.

Correspondence: J-L. Vincent

Dept of Intensive Care

Erasme University Hospital

Route de Lennik 808

B-1070 Brussels

Belgium

Keywords: Acute respiratory distress syndrome

acute respiratory failure

multiple organ failure

sepsis

Received: September 21996

Accepted after revision February 211997

\section{Methods}

Over a 2 year period (1993-1995), in our 31 bed ICU, 129 patients were treated for ARDS, as defined by the following standard criteria [21]: 1) respiratory failure of acute onset; 2$)$ arterial oxygen tension $\left(\mathrm{Pa}_{\mathrm{a}} \mathrm{O}_{2}\right)$ /inspiratory oxygen fraction $\left(F \mathrm{I}, \mathrm{O}_{2}\right)$ of $\leq 26.7 \mathrm{kPa}(200 \mathrm{mmHg})$, regardless of the level of positive end-expiratory pressure (PEEP); 3) bilateral diffuse infiltrates on frontal chest radiograph; 4) a pulmonary artery wedge pressure of $\leq$ $18 \mathrm{mmHg}$, or no clinical evidence of congestive heart failure; and 5) no history or evidence of chronic lung disease, such as interstitial pulmonary fibrosis, cystic fibrosis, established chronic obstructive lung disease or primitive pulmonary artery hypertension.

Data compiled for each patient included: demographic information (age, sex, length of stay in the intensive care unit); pre-existing diseases; causes of ARDS; degree of organ failure; and ventilatory parameters. Outcome was assessed at the time of discharge from the ICU. In the nonsurvivors, the causes of death and the last blood gas values before the agonal period were recorded.

A pulmonary source of infection was defined as the presence of new or changing infiltrates on chest radiograph, and sputum or bronchoalveolar lavage fluid with leucocytes and pathogenic organisms in Gram stain 
and/or culture. The definition of sepsis was similar to that used in the studies by Montgomery et al. [3], Suchyta et al. [9] and Milberg et al. [1], and included the presence of two of the following: an abnormal temperature $\left(>38.5\right.$ or $\left.<36^{\circ} \mathrm{C}\right)$; an abnormal white blood cell (WBC) count $\left(<3,000\right.$ or $>12,000$ cells $\left.\cdot \mathrm{mm}^{-3}\right)$; the presence of positive cultures (blood or other sites); plus one sign of systemic response, such as prolonged hypotension, otherwise unexplained, a low systemic vascular resistance $\left(<800\right.$ dynes $\left.\cdot \mathrm{s} \cdot \mathrm{cm}^{-5}\right)$, or hyperlactataemia (lactate $\left.>2 \mathrm{mEq} \cdot \mathrm{L}^{-1}\right)$.

Refractory hypoxaemia was defined by a $\mathrm{Pa}, \mathrm{O}_{2}<8.0$ $\mathrm{kPa}(60 \mathrm{mmHg})$ at an $F \mathrm{I}, \mathrm{O}_{2}$ of $\geq 0.9$ after adjustment of ventilatory conditions, including the PEEP level, and in the absence of cardiovascular collapse. Organ system failure was determined by the following criteria: 1) renal failure in the presence of a creatinine $>3.5 \mathrm{mg} \cdot \mathrm{dL}^{-1}$, anuria, or the need for dialysis or haemofiltration; 2) cardiovascular failure when vasopressor agents were required or an acute myocardial infarction was demonstrated; 3) coagulation failure with a platelet count $<60,000$ platelets $\cdot \mathrm{mm}^{-3}$ and prothrombin time or activated partial thromboplastin time $>1.5$ times the control value; 4) central nervous system failure with a Glasgow coma score $<8$ (estimated in the absence of sedation); 5) hepatic failure if total bilirubin $>5 \mathrm{mg} \cdot \mathrm{dL}^{-1}$ and prothrombin time or activated partial thromboplastin time $>1.5$ times control; 6) gastrointestinal failure in the presence of pancreatitis or gastrointestinal haemorrhage requiring more than two units of packed red blood cell replacement. MOF was defined by the co-existence of three or more such organ dysfunctions.

Data were analysed by Student's t-test, the Chi-squared method, and the Yates correction. Differences were considered statistically significant at a p-value less than 0.05 .

\section{Results}

A total of 129 patients was studied, including 62 (48\%) survivors and $67(52 \%)$ nonsurvivors (table 1). On average, the survivors were younger than the nonsurvivors: 52 out of $93(56 \%)$ patients younger than 65 yrs survived, but only 10 out of $36(28 \%)$ patients older than 65 yrs survived (differences $\mathrm{p}<0.01$ ). ARDS had a worse prognosis in medical patients than in surgical/trauma patients (table 1) $(\mathrm{p}<0.02)$. The mortality rate was $44 \%$ in 1993 and $57 \%$ in 1994 (NS).

Since a total of 2,546 patients were admitted in 1993 and 2,540 patients in 1994, the ARDS patients represented 2.0 and $2.7 \%$ of all ICU admissions, respectively. Of these patients, $73 \%$ were male (table 1).

The causes of ARDS are presented in table 2. ARDS secondary to sepsis (pulmonary or nonpulmonary) had a worse prognosis than other forms.

Table 3 presents the causes of death in relation to the cause of ARDS. A total of 33 patients $(49 \%)$ died from MOF. Eleven patients $(16 \%)$ died from respiratory failure: 10 of these died from refractory hypoxaemia (last $P$ a, $\mathrm{O}_{2} 6.2 \pm 1.2 \mathrm{kPa}$ $(46.8 \pm 9.1 \mathrm{mmHg})$ at a $\mathrm{FI}, \mathrm{O}_{2}$ of at least $\left.90 \%\right)$ and one from tension pneumothorax. Five of the 11 patients also had MOF. Ten patients died of cardiac problems, including seven patients who had a fatal arrhythmia (two myocardial infarction, one right ventricular failure, and

Table 1. - Demographic characteristics of ARDS patients

\begin{tabular}{lcc}
\hline & Survivors & Nonsurvivors \\
\hline Patients n $(\%)$ & $62(48)$ & $67(52)$ \\
Sex F/M & $15 / 47$ & $20 / 47$ \\
Age yrs & $47 \pm 17$ & $58 \pm 15^{*}$ \\
ICU stay days & $17 \pm 17$ & $13 \pm 24$ \\
Surgical/trauma/medical n & $34 / 12 / 16$ & $27 / 7 / 33^{*}$ \\
\hline
\end{tabular}

ICU: intensive care unit; F: female; M: male; ARDS: acute respiratory distress syndrome. $*$ : $\mathrm{p}<0.05$, compared to survivors.

Table 2. - Causes of ARDS

\begin{tabular}{|c|c|c|c|}
\hline & $\begin{array}{l}\text { Survivors } \\
(\mathrm{n}=62)\end{array}$ & $\begin{array}{l}\text { Nonsurvivors } \\
\qquad(n=67)\end{array}$ & $\begin{array}{c}\text { Total } \\
(\mathrm{n}=129)\end{array}$ \\
\hline Sepsis (nonpulmonary) & $10(16)$ & $22(33)$ & $32(25)$ \\
\hline Abdominal & 5 & 11 & 16 \\
\hline Urinary & 1 & 4 & 5 \\
\hline Catheter & 1 & 2 & 3 \\
\hline Endocarditis & - & 2 & 2 \\
\hline Pelvic abscess & 1 & - & 1 \\
\hline Cellulitis & - & 1 & 1 \\
\hline Unknown & 2 & 2 & 4 \\
\hline Elective surgery & $21(34)$ & $9(13)^{*}$ & $30(23)$ \\
\hline Cardiac & 13 & 4 & 17 \\
\hline Vascular & 5 & 1 & 6 \\
\hline Thoracic & 2 & 3 & 5 \\
\hline Abdominal & 1 & 1 & 2 \\
\hline Pulmonary infection & $4(6)$ & $14(21)^{*}$ & $18(14)$ \\
\hline Trauma & $14(23)$ & $4(6)^{*}$ & $18(14)$ \\
\hline Gastrointestinal haemorrhage & $3(5)$ & $6(9)$ & $9(7)$ \\
\hline Neurogenic & $4(6)$ & $4(6)$ & $8(6)$ \\
\hline Inhalation & $3(5)$ & $2(3)$ & $5(4)$ \\
\hline Pancreatitis & $2(3)$ & $2(3)$ & $4(3)$ \\
\hline Others & $1(2)$ & $4(6)$ & $5(4)$ \\
\hline OKT3 therapy & 1 & - & 1 \\
\hline Near-drowning & - & 1 & 1 \\
\hline Carcinomatous lymphangitis & - & 3 & 3 \\
\hline
\end{tabular}

Values are presented as absolute numbers, and percentages in parentheses. ARDS: acute respiratory distress syndrome. *: $\mathrm{p}<0.05$, compared to survivors.

Table 3. - Relationships between causes of ARDS and causes of death

\begin{tabular}{lrrrrrrr}
\hline Causes of ARDS & MOF & Resp. & Card. & Neur. & Haem. & Neopl. & Total \\
\hline Sepsis (nonpulmonary) & 15 & 1 & 3 & 2 & 1 & - & 22 \\
Pulmonary infection & 6 & 4 & 2 & 1 & - & 1 & 14 \\
Surgery & 3 & 1 & 4 & - & 1 & - & 9 \\
Trauma & 4 & - & - & - & - & - & 4 \\
Gastrointestinal & 3 & 2 & - & - & 1 & - & 6 \\
haemorrhage & - & - & - & 4 & - & - & 4 \\
Neurogenic & 1 & 1 & - & - & - & - & 2 \\
Inhalation & 1 & - & 1 & - & - & - & 2 \\
Pancreatitis & - & 1 & - & - & - & - & 1 \\
Near-drowning & - & 1 & - & - & - & 2 & 3 \\
Carcinomatous & & & & & & & \\
lymphangitis & 33 & 11 & 10 & 7 & 3 & 3 & 67 \\
Total & $(49)$ & $(16)$ & $(15)$ & $(10)$ & $(4)$ & $(4)$ & $(100)$ \\
\end{tabular}

Values are presented as absolute number, and percentage in parenthesis. ARDS: acute respiratory distress syndrome; MOF: multiple organ failure; Resp: respiratory failure; Card: cardiac problems; Neur: neurological dysfunction; Haem: haemorrhage; Neopl: neoplasm. 
two after recent cardiac surgery, and two other patients), and three patients who developed a cardiogenic shock (one right ventricular failure after pneumectomy and two ischaemic cardiomyopathies). Seven patients died of neurological dysfunction (three from head trauma, three from intracranial haemorrhage, and one from subarachnoid haemorrhage), and three from haemorrhage (one after tracheotomy, one after peripheric vascular by-pass, and one from recurrent gastrointestinal haemorrhage). In three patients, life support was withdrawn in view of the development of MOF in patients with underlying neoplasm.

Nonsurvivors had a higher number of failing organs than the survivors (fig. 1). A total of 49 of the 67 nonsurvivors $(73 \%)$ had MOF. The most frequent complications were cardiovascular failure and acute renal failure

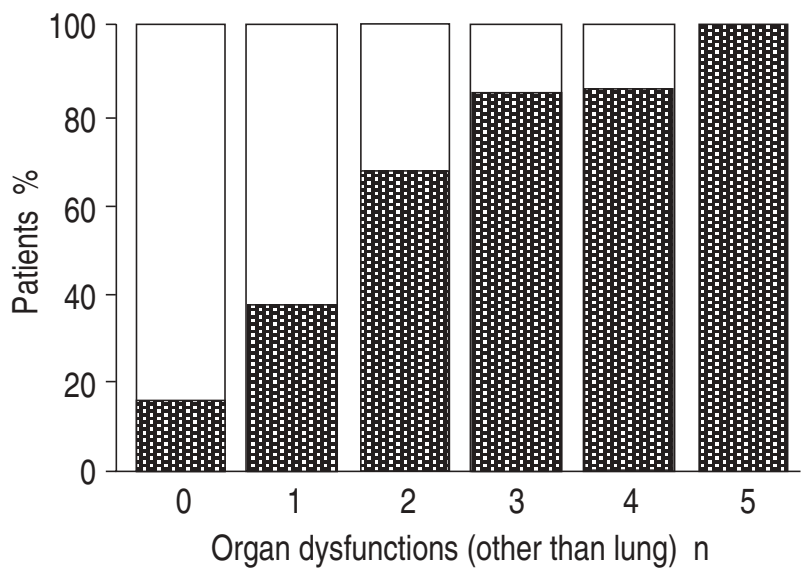

Fig. 1. - Percentage of survivors ( $\square$ ) and nonsurvivors ( 䀧明 ) for each number of organ dysfunctions.

Table 4. - Type of organ dysfunctions

\begin{tabular}{lcc}
\hline & $\begin{array}{c}\text { Survivors } \\
(\mathrm{n}=62)\end{array}$ & $\begin{array}{c}\text { Nonsurvivors } \\
(\mathrm{n}=67)\end{array}$ \\
\hline Cardiovascular & 9 & $45^{*}$ \\
Renal & 13 & $42^{*}$ \\
Coagulation & 11 & $30^{*}$ \\
Cerebral & 12 & $26^{*}$ \\
Liver & 3 & $20^{*}$ \\
Gastrointestinal & 6 & 10
\end{tabular}

*: $\mathrm{p}<0.05$, compared to survivors.

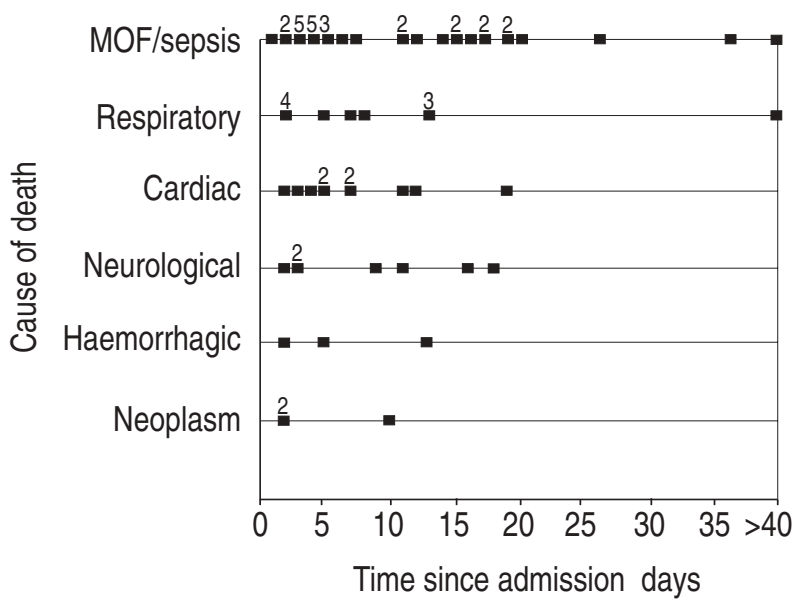

Fig. 2. - Relationship between cause of death and duration of stay in the intensive care unit (ICU). $\mathbf{m}: 1$ death; $\mathbf{x}$ : $\mathbf{x}$ deaths. MOF: multiple organ failure. (table 4). Figure 2 presents the day of death after ICU admission for each cause of death. MOF was not always a late event, since 16 out of $33(48 \%)$ patients with MOF died within the first 5 days of admission.

\section{Discussion}

The presentation and pattern of ARDS may have changed with time, in relation to differences in patient population or therapeutic interventions. The present study emphasized that ARDS, as defined by strict criteria [21], is a relatively rare syndrome. The $2-3 \%$ incidence of ARDS in all ICU admissions is in agreement with figures reported in other studies [2]. In view of the large size of our ICU, we were able to collect a cohort of 129 patients, larger than in many other series $[3,4,6,16$, 18-20]. The primary cause of ARDS in the present study, as in many other studies [2, 5, 6, 10, 11], was sepsis of nonpulmonary origin, followed by surgical complications, pulmonary infection and major trauma.

Some authors $[1,2]$ suggested recently that the mortality rate of ARDS may have decreased during the past two decades, a trend first noted by Suchyta and coworkers [8, 9]. Studies from 1978-1983 [3-6, 20] reported mortality rates ranging $61-74 \%$, and more recent studies have reported values that are usually between 50 and $60 \%[7-14,17,18]$, and even below $40 \%$ [1, 2, 19]. As proposed by KNAUS et al. [2], low mortality rates in some studies may be the result of the inclusion of patients with a less severe degree of hypoxaemia $\left(\mathrm{Pa}_{\mathrm{a}} \mathrm{O}_{2} /\right.$ $\left.\mathrm{FI}, \mathrm{O}_{2}<40.0 \mathrm{kPa}(300 \mathrm{mmHg})\right)$ and/or inclusion of a larger proportion of postoperative and trauma patients. We observed a mortality rate of $52 \%$, which is within the range observed in other studies [7-14, 17, 18, 22, 23].

The severity of ARDS depends on the underlying disease and the degree of physiological impairment. As expected, old age was associated with a worse prognosis $[2,6,7,9,11]$. In our experience, survival from ARDS was higher after trauma or surgery than in the medical patients. KNAus et al. [2] and ArTigas et al. [7] reported similar observations. Hudson et al. [23] proposed that the reduction in mortality over time is particularly significant in patients with trauma. We further observed that patients with a noninfectious aetiology of ARDS had a better prognosis than those with ARDS due to sepsis or pulmonary infection.

MOF was the principal cause of death, accounting for roughly half of the fatalities. These observations agree with others showing a strong link between MOF (usually associated with sepsis) and subsequent death in patients with ARDS [3, 6, 13, 19, 20]. As in other studies, the severity of organ dysfunction was directly related to the likelihood of death $[2,3,6,9,19,20,22]$. In our study, all patients with failures in six organs died. Nevertheless, it is interesting to note that death from MOF did not always occur late, since most occurred in the first 5 days after admission. As in the studies by MANCEBO and ARTigas [6] and Knaus et al. [2], the most frequent complications in the nonsurvivors were cardiovascular and acute renal failure. Recently, Doyle et al. [22] identified nonpulmonary organ system dysfunction as the first factor associated with increased mortality.

Only 1 out of 6 patients with ARDS died from the inability to ensure adequate gas exchange, as defined 
by a $\mathrm{Pa}, \mathrm{O}_{2}<8.0 \mathrm{kPa}(60 \mathrm{mmHg})$ at a $F \mathrm{I}, \mathrm{O}_{2}>0.9$. These figures are remarkably similar to those produced by MONTGOMERY et al. [3] more than 10 yrs ago in a smaller group of 47 patients. They are also similar to the recent experience at the University of Washington [23, 24]. In contrast, other studies $[4,9]$ have found respiratory failure to be the leading cause of death. FowLER et al. [4] reported that $75 \%$ of fatal events were attributable to respiratory failure, which was, however, loosely defined as a combination of hypoxaemia and nosocomial infections. Suchyta and co-workers [9] reported that respiratory failure accounted for $40 \%$ of fatal events, and proposed the relatively high incidence of pneumonia in their population (41\%) as a possible explanation. In our study, only $14 \%$ of ARDS cases were due to pneumonia, but refractory hypoxaemia was the leading cause of death in these patients. Thus, the two studies concur in indicating that refractory hypoxaemia is a more common cause of death when ARDS is due to pneumonia.

It is reasonable to question whether extracorporeal techniques can improve the outcome from ARDS. In our study, over a period of more than 2 yrs, only 11 patients died of irreversible respiratory failure. Five of these patients had MOF including coagulation problems, which may be a relative contraindication to extracorporeal techniques [12-15]. Hence, such techniques would have prevented a terminal hypoxic event in very few patients in the present study. Obviously, extracorporeal support may offer advantages other than the prevention of terminal hypoxia. Although most groups using $\mathrm{ECMO}$ or $\mathrm{ECCO}_{2} \mathrm{R}$ have reported survival rates of about $50 \%$ [12-14], a figure similar to ours, the only way to define the role of extracorporeal support is to perform a randomized trial. One such trial recently [15] failed to demonstrate a survival benefit associated with $\mathrm{ECCO}_{2} \mathrm{R}$. Since refractory hypoxaemia is more commonly lethal in patients with pneumonia, these patients may be good candidates for such a study.

Since sepsis remains the primary cause of death in patients with acute respiratory distress syndrome, prevention and treatment of sepsis should represent a first priority to improve outcome from this condition.

\section{References}

1. Milberg JA, Davis DR, Steinberg KP, Hudson LD. Improved survival of patients with acute respiratory distress syndrome (ARDS): 1983-1993. JAMA 1995; 273 : 306-309.

2. Knaus WA, Sun X, Hakim RB, Wagner DP. Evaluation of definitions for adult respiratory distress syndrome. Am J Respir Crit Care Med 1994; 150: 311-317.

3. Montgomery BA, Stager MA, Carrico J, et al. Causes of mortality in patients with the adult respiratory distress syndrome. Am Rev Respir Dis 1985; 132: 485-491.

4. Fowler AA, Hamman RF, Good JT, Benson KN. Adult respiratory distress syndrome: risk with common predispositions. Ann Intern Med 1983; 98: 593-597.

5. Pepe PE, Potkin RT. Clinical predictors of the adult respiratory distress syndrome. Am J Surg 1982; 144: 124-130.

6. Mancebo J, Artigas A. A clinical study of the adult respiratory distress syndrome. Crit Care Med 1987; 15: 243-246.

7. Artigas A. Adult respiratory distress syndrome: changing concepts in clinical evolution and recovery. In: Vincent JL, ed. Update 1988: "Update in Intensive Care and Emergency Medicine". Berlin, Heidelberg, New York, Springer Verlag, 1988; pp. 97-114.

8. Suchyta MR, Clemmer TP, Orme JF, Morris AH, Elliot CG. Increased survival of ARDS patients with severe hypoxemia (ECMO criteria). Chest 1991; 99: 951-955.

9. Suchyta MR, Clemmer TP, Elliot CG, Orme JF, Weaver LK. The adult respiratory distress syndrome: a report of survival and modifying factors. Chest 1992; 101: 1074-1079.

10. Villar J, Slutsky AS. The incidence of the adult respiratory distress syndrome. Am Rev Respir Dis 1989; 140: 814-816.

11. Sloane PJ, Gee MH, Gottlieb JE, et al. A multicenter registry of patients with acute respiratory distress syndrome: physiology and outcome. Am Rev Respir Dis 1992; 146: 419-426.

12. Gattinoni L, Pesenti A, Mascheroni D, et al. Low frequency positive pressure ventilation with extracorporeal $\mathrm{CO}_{2}$ removal in severe acute respiratory failure. JAMA 1986; 256: 881-886.

13. Brunet F, Belgith M, Mira J, et al. Extracorporeal carbon dioxide removal and low-frequency positive-pressure ventilation. Chest 1993; 104: 889-898.

14. Wagner P, Knoch M, Sangmeister C, Muller E, Lennartz $\mathrm{H}$, Rothmund M. Extracorporeal gas exchange in adult respiratory distress syndrome: associated morbidity and its surgical treatment. Br J Surg 1990; 77: 1395-1398.

15. Morris AH, Wallace CJ, Menlove RL, et al. Randomized clinical trial of pressure-controlled inverse ratio ventilation and extracorporeal $\mathrm{CO}_{2}$ removal for adult respiratory distress syndrome. Am J Respir Crit Care Med 1994; 149: 295-305.

16. Lee J, Turner JS, Morgan CJ, Keogh BF, Evans TW. Adult respiratory distress syndrome. Has there been a change in outcome predictive measures? Thorax 1994; 49: 596-597.

17. Bone RC, Fisher CJ, Clemmer TP, Slotman GJ, Metz GA, and the Methylprednisolone Severe Sepsis Study Group. Early methylprednisolone treatment for septic syndrome and the adult respiratory distress syndrome. Chest 1987; 92: 1032-1036.

18. Bone RC, Slotman G, Maunder R, Silverman H, Hyers TM, Kerstein MD. Randomized double-blind, multicenter study of prostaglandin $\mathrm{E}_{1}$ in patients with the adult respiratory distress syndrome. Chest 1989; 96: 114-119.

19. Hickling KG, Walsch J, Henderson S, Jackson R. Low mortality rate in adult respiratory distress syndrome using low-volume, pressure-limited ventilation with permissive hypercapnia: a prospective study. Crit Care Med 1994; 22: 1568-1578.

20. Bell RC, Coalson JJ, Smith JD, et al. Multiple organ system failure and infection in adult respiratory distress syndrome. Ann Intern Med 1983; 99: 293-298.

21. Bernard GR, Artigas A, Brigham KL, et al. Report of the American-European consensus conference on acute respiratory distress syndrome: definitions, mechanisms, relevant outcomes, and clinical trial co-ordination. J Crit Care 1994; 9: 72-81.

22. Doyle LA, Szaflarski N, Modin GW, Wiener-Kronish J, Matthay MA. Identification of patients with acute lung injury. Predictors of mortality. Am J Respir Crit Care Med 1995; 152: 1818-1824.

23. Hudson LD, Milberg JA, Anardi D, Maunder RJ. Clinical risks for development of the acute respiratory distress syndrome. Am J Respir Crit Care Med 1995; 151: 293-301.

24. Wang BM, Steinberg KP, Hudson LD. Causes of mortality in patients with the acute respiratory distress syndrome (ARDS): 1981-1994 (Abstract). Am Rev Respir Crit Care Med 1996; 153: A593. 